\title{
Clinical validation of dialysable calcium in relation to other methods of serum calcium measurement
}

\author{
R L PRINCE, S R LANGTON
}

\begin{abstract}
Dialysable calcium (CaD) values were measured by a simple technique not interfered with by protein bound calcium and validation attempted by comparison with concentrations of ionised calcium ( $\mathrm{CaI}$ ) and clinical categorisation. $\mathrm{CaD}$ values were also compared with total calcium (CaT) and albumin adjusted calcium ( $\mathrm{CaA}$ ) concertrations. The normal ranges for $\mathrm{CaD}, \mathrm{CaT}, \mathrm{CaA}$, and CaI were calculated from the results in healthy blood donors. In 50 normal subjects $\mathrm{CaD}$ was more highly correlated with $\mathrm{CaI}$ than $\mathrm{CaT}$ or $\mathrm{CaA}$. The effects of lying down and of venous stasis in 10 normal subjects showed that $\mathrm{CaD}$ was slightly influenced by posture only, whereas CaT was noticeably affected by posture and venous stasis; $\mathrm{CaA}$ reduced but did not abolish these effects on CaT. The correlation coefficient of $\mathrm{CaD}$ and $\mathrm{CaI}$ in patients with chronic renal failure was 0.81. CaD was compared with $\mathrm{CaT}$ and $\mathrm{CaA}$ values in 293 consecutive hospital patients; discrepant results were obtained in $14.3 \%$ and $13.0 \%$ of cases respectively and there were some clinical grounds for accepting $\mathrm{CaD}$ as correct in $86 \%$ and $74 \%$ of these cases.

Measurement of $\mathrm{CaD}$ is a simple, reliable method for estimating accurately the calcium concentration free from biologically inactive protein bound calcium.
\end{abstract}

\section{Introduction}

Although total serum calcium estimations in routine clinical laboratories have reached a high degree of precision, it has been

\footnotetext{
Department of Medicine, Sir Charles Gairdner Hospital, Nedlands. Western Australia 6009

R L PRINCE, MD, FRACP, senior lecturer

Department of Biochemistry, Fremantle Hospital, Fremantle, Western Australia

S R LANGTON, BSC, FAACB, chief technologist

Correspondence to: Dr R L Prince.
}

known for 50 years that the calcium bound to albumin and globulin-that is, roughly $40 \%$ of the total-is biologically inactive. ${ }^{1}$ A continuous flow method for measuring dialysable calcium $(\mathrm{CaD})$ was first described in 1977." In this method ionised calcium, accounting for about half of the total calcium, and complex bound calcium, accounting for about $10 \%$ of the total calcium, are measured. The complex bound calcium is mainly in association with bicarbonate ${ }^{3}$ and to a less extent citrate and lactate. Despite the technical simplicity of this method and the fact that it is not influenced by calcium bound to plasma proteins it has not received widespread interest. We describe our experience in measuring $\mathrm{CaD}$ in various clinical settings and relate it to the concurrent measurement of total calcium $(\mathrm{CaT})$, albumin adjusted calcium $(\mathrm{CaA})$, and ionised calcium $(\mathrm{CaI})$. Also we try to validate the use of $\mathrm{CaD}$, firstly, by relating it to $\mathrm{CaI}$ and, secondly, by relating it to the clinical state of the patient.

\section{Methods}

CaD concentration was measured by the method of Toffaletti and coworkers, ${ }^{45}$ except that the sample buffer was changed from tris(hydroxymethyl)aminomethane (TRIS) to imidazole (P T Flett, N D H Balazs, personal communication). In brief, the method is a modification of the Technicon AutoAnalyzer II method for $\mathrm{CaT}$, which is based on the dialysis of calcium across a semipermeable cuprophane membrane and measurement colorimetrically using cresolphthalein complexone. Instead of adding a low $\mathrm{pH}$ buffer to the sample to release all protein bound calcium and hence measuring $\mathrm{CaT}$, a $0.8 \mathrm{M}$ imidazole donor buffer at $\mathrm{pH} 7.4$ was added to the sample stream. This had the effect of buffering the patient's serum towards a normal $\mathrm{pH}$ and thereby stabilising the normal equilibrium between bound and free calcium at that $\mathrm{pH}$. Further to stabilise this equilibrium and reduce dialysis effects the donor buffer contained calcium carbonate $1.4 \mathrm{mmol} / 1 \quad(5.6 \mathrm{mg} / 100 \mathrm{ml})$. An AutoAnalyzer II manifold incorporating a $15 \mathrm{~cm}$ dialysis membrane was used. The recipient buffer was $0.025 \mathrm{M}$ imidazole $\mathrm{pH} 7 \cdot 4$. The chromagen cresolphthalein complexone was mixed with aminomethylpropanol buffer to prevent the pumping and mixing artefacts experienced when these were pumped separately and mixed on line. The chromagen used was shown to produce linear results up to a calcium concentration of $3.0 \mathrm{mmol} / 1(12.0 \mathrm{mg} / 100 \mathrm{ml})$. A primary $1.4 \mathrm{mmol} / 1(5.6 \mathrm{mg} / 100 \mathrm{ml})$ calcium carbonate standard (National Bureau of Standards, USA) was used and secondary calcium standards 
of 1.31 and $1.57 \mathrm{mmol} / 1(5.24$ and $6.28 \mathrm{mg} / 100 \mathrm{ml})$ prepared from pooled patients' serum; these were used on a day to day basis. The between run coefficient of variation was $0.7 \%$ for the $1.31 \mathrm{mmol} / \mathrm{l}$ standard and $1.1 \%$ for the $1.57 \mathrm{mmol} / 1$ standard. Serum samples were collected from subjects without any special precautions and $500 \mu l$ placed in the autoanalyser cups to accommodate the aspiration volume of $400 \mu \mathrm{l}$.

$\mathrm{CaT}$ was assayed on a Corning 940 calcium titrator, in which the calcium in the sample complexed with fluorescein complexone to produce a green fluorescence. This was automatically titrated back to a non-fluorescent end point using ethylene glycol tetra-acetic acid. The volume of ethylene glycol tetra-acetic acid used was proportional to the calcium concentration. The interassay coefficient of variation at $1.94 \mathrm{mmol} / 1(7.76 \mathrm{mg} / 100 \mathrm{ml})$ was $1.4 \%$ and at $2.83 \mathrm{mmol} / 1$ $(11.32 \mathrm{mg} / 100 \mathrm{ml}) 1.3 \%$. Albumin assays were performed on a Cobas-Bio Analyser using a bromocresol green succinate buffer reagent with the reading taken at 15 seconds. The interassay coefficient of variation was $2.5 \%$ at $28 \mathrm{~g} / \mathrm{l}$ and $2 \cdot 1 \%$ at $45 \mathrm{~g} / \mathrm{l}$. CaA was calculated from the formula $\mathrm{CaA}=\mathrm{CaT}+(40$-albumin value in $\mathrm{g}) \times$ $0.02 .^{6} \mathrm{CaI}$ was measured on a Nova 2 calcium specific electrode. Samples for this procedure were collected anaerobically, stored at $4^{\circ} \mathrm{C}$, and analysed within four hours. In this method no $\mathrm{pH}$ correction was employed, so that the $\mathrm{CaI}$ concentration was assumed to be measured close to the $\mathrm{pH}$ of the patient's serum.

Analysis of clinical categorisation was by review of the case notes of discordant cases. Correlation coefficients were calculated by the method of least squares analysis. Statistical evaluation of results was by paired or unpaired Student's $t$ test, as appropriate.

\section{Results}

Figure 1 gives the results of $\mathrm{CaD}, \mathrm{CaT}$, and $\mathrm{CaA}$ estimations in 263 healthy blood donors (135 men, 128 women) aged 18 to 65 . Figure 2 gives the results of CaI estimations in a separate group of 120 blood donors ( $60 \mathrm{men}$ ) aged 18 to 65 . The normal range for each type of calcium measurement was defined as the mean and two standard deviations. The variance of the normal range of $\mathrm{CaD}$ was much smaller than for $\mathrm{CaT}$ or $\mathrm{CaA}$ but similar to that for $\mathrm{CaI}$. Furthermore,
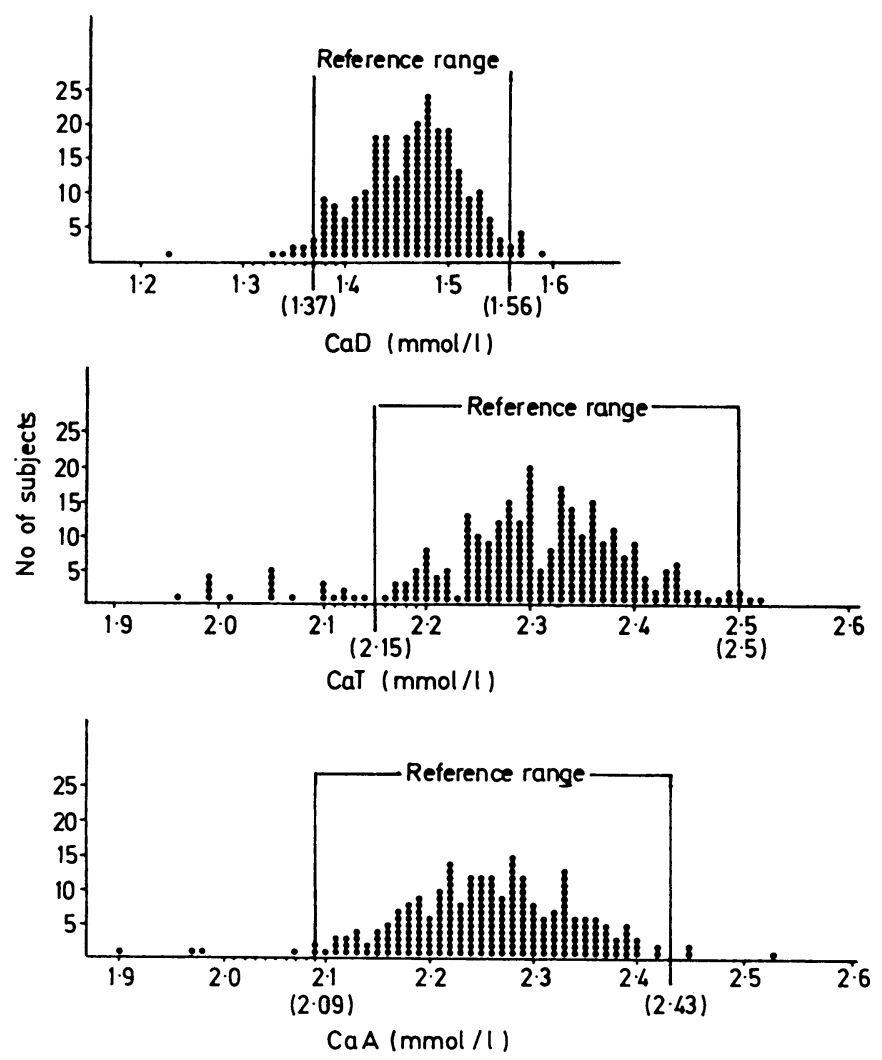

FIG 1-Distribution of concentrations of dialysable calcium (CaD), total calcium (CaT), and adjusted calcium $(\mathrm{CaA})$ in healthy group of 135 men and 128 women blood donors.

Conversion: SI to traditional units-Calcium: $1 \mathrm{mmol} / 1 \approx 4 \mathrm{mg} / 100 \mathrm{ml}$.

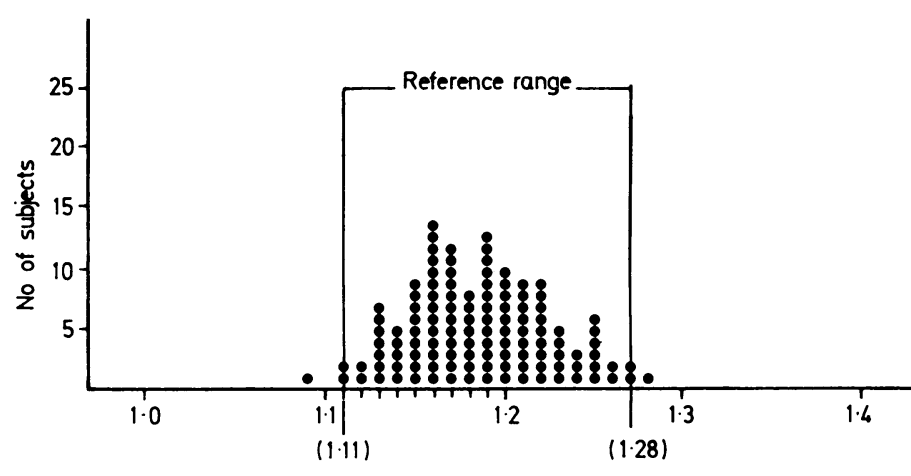

Cal $(\mathrm{mmol} / \mathrm{l})$

FIG 2-Distribution of concentrations of ionised calcium (CaI) in healthy group of 60 men and 60 women blood donors.

Conversion: SI to traditional units-Calcium: $1 \mathrm{mmol} / 1 \approx 4 \mathrm{mg} / 100 \mathrm{ml}$.

Mean and SD (in parentheses) of normal ranges for men and women blood donors

\begin{tabular}{lll} 
& \multicolumn{1}{c}{ Men } & Women \\
\hline Dialysable calcium (CaD; mmol/l) & $1.47(0.05)$ & $1.46(0.06)$ \\
Total calcium (CaT; mmol/1) & $2.34(0.09)$ & $2.29(0.08)$ \\
Albumin adjusted calcium (CaA; mmol/l) & $2.28(0.08)$ & $2.22(0.08)$ \\
Ionised calcium (CaI; mmol/l) & $1.19(0.04)$ & $1.19(0.04)$ \\
\hline
\end{tabular}

- Difference from value in men $\mathbf{p}<0.001$.

Conversion: SI to traditional units-Calcium: $1 \mathrm{mmol} / 1 \approx 4 \mathrm{mg} / 100 \mathrm{ml}$.

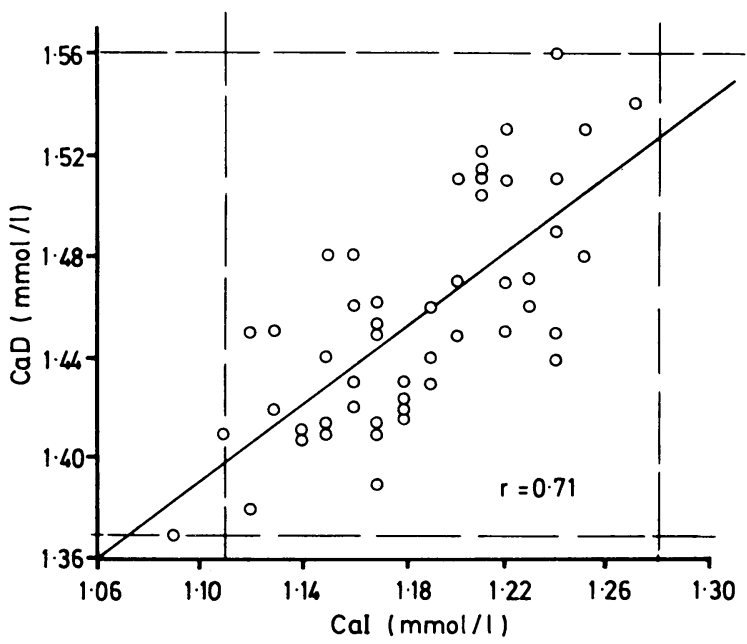

FIG 3-Correlation of ionised calcium (CaI) and dialysable calcium $(\mathrm{CaD})$ concentrations in $\mathbf{5 0}$ healthy volunteers.

Conversion: $S I$ to traditional units-Calcium: $1 \mathrm{mmol} / 1 \approx 4 \mathrm{mg}$ / $100 \mathrm{ml}$.

there was no significant difference in the normal range for $\mathrm{CaD}$ or $\mathrm{CaI}$ between men and women, whereas the normal ranges for $\mathrm{CaT}$ and $\mathrm{CaA}$ were significantly higher for men than for women (table).

A further study of healthy volunteers aged 20 to 69 was made in which $\mathrm{CaI}$ was measured concurrently with $\mathrm{CaD}, \mathrm{CaT}$, and $\mathrm{CaA}$. There were 50 subjects in all ( 13 women, 37 men), and figure 3 shows the correlation between $\mathrm{CaI}$ and $\mathrm{CaD}$ values. The correlation coefficient was 0.71 , whereas the correlations between $\mathrm{CaI}$ and $\mathrm{CaT}$ and $\mathrm{CaA}$ in the same subjects were 0.48 and 0.41 , respectively.

Figure 4 shows the effects of lying down and of venous stasis produced by inflating a sphygmomanometer cuff to halfway between systolic and diastolic blood pressure in five healthy men and five healthy women. In this study $\mathrm{CaI}$ was not measured. As expected, the changes in CaT concentration closely followed those for albumin. $\mathrm{CaA}$ showed a small effect of posture and venous stasis, while $\mathrm{CaD}$ was slightly affected by posture only.

The correlation between $\mathrm{CaI}$ and $\mathrm{CaD}$ was studied in 23 patients receiving haemodialysis for chronic renal failure. The correlation 
coefficient of $\mathrm{CaI}$ and $\mathrm{CaD}$ was 0.89 , similar to the correlation coefficients of $\mathrm{CaI}$ and $\mathrm{CaT}$ and of $\mathrm{CaI}$ and $\mathrm{CaA}(0.89$ and 0.87 , respectively).

The validity of $\mathrm{CaD}$ was compared with $\mathrm{CaT}$ and $\mathrm{CaA}$ in 293 consecutive hospital patients. The correlation coefficient between $\mathrm{CaD}$ and $\mathrm{CaT}$ was 0.86 (see fig 5). The normal ranges, derived from the blood donor population for $\mathrm{CaD}$ and $\mathrm{CaT}$, are shown in figure 5 , as are areas of discrepancy between $\mathrm{CaD}$ and $\mathrm{CaT}$ in which the value of $\mathrm{CaD}$ or $\mathrm{CaT}$ was low or high compared with a normal value of the other.

Area 1-Eighteen patients had normal $\mathrm{CaD}$ and high $\mathrm{CaT}$ values. In 13 cases the high $\mathrm{CaT}$ value was associated with a high albumin concentration and corrected into the normal range with $\mathrm{CaA}$. A lower in the hospital patients (many of whom were supine) than in the healthy ambulant blood donors. Furthermore, using the normal range derived from the $\mathrm{CaT}$ normal range for $\mathrm{CaA}$ is a widespread practice. The areas of discrepancy between $\mathrm{CaD}$ and $\mathrm{CaA}$ values are indicated in figure 6.

Area 1 -Eight patients had normal $\mathrm{CaD}$ and high $\mathrm{CaA}$ values. In three patients the $\mathrm{CaT}$ concentration was normal, and in these there was no reason to suspect an abnormality of calcium metabolism. Two other patients had myeloma with raised immunoglobulin values. The remaining three were cases of apnoea in a neonate, Paget's disease, and inflammatory arthropathy.

Area 2 - Of 12 patients with high $\mathrm{CaD}$ and normal $\mathrm{CaA}$ values, three had recurrent renal calculi and may have had primary hyperpara-
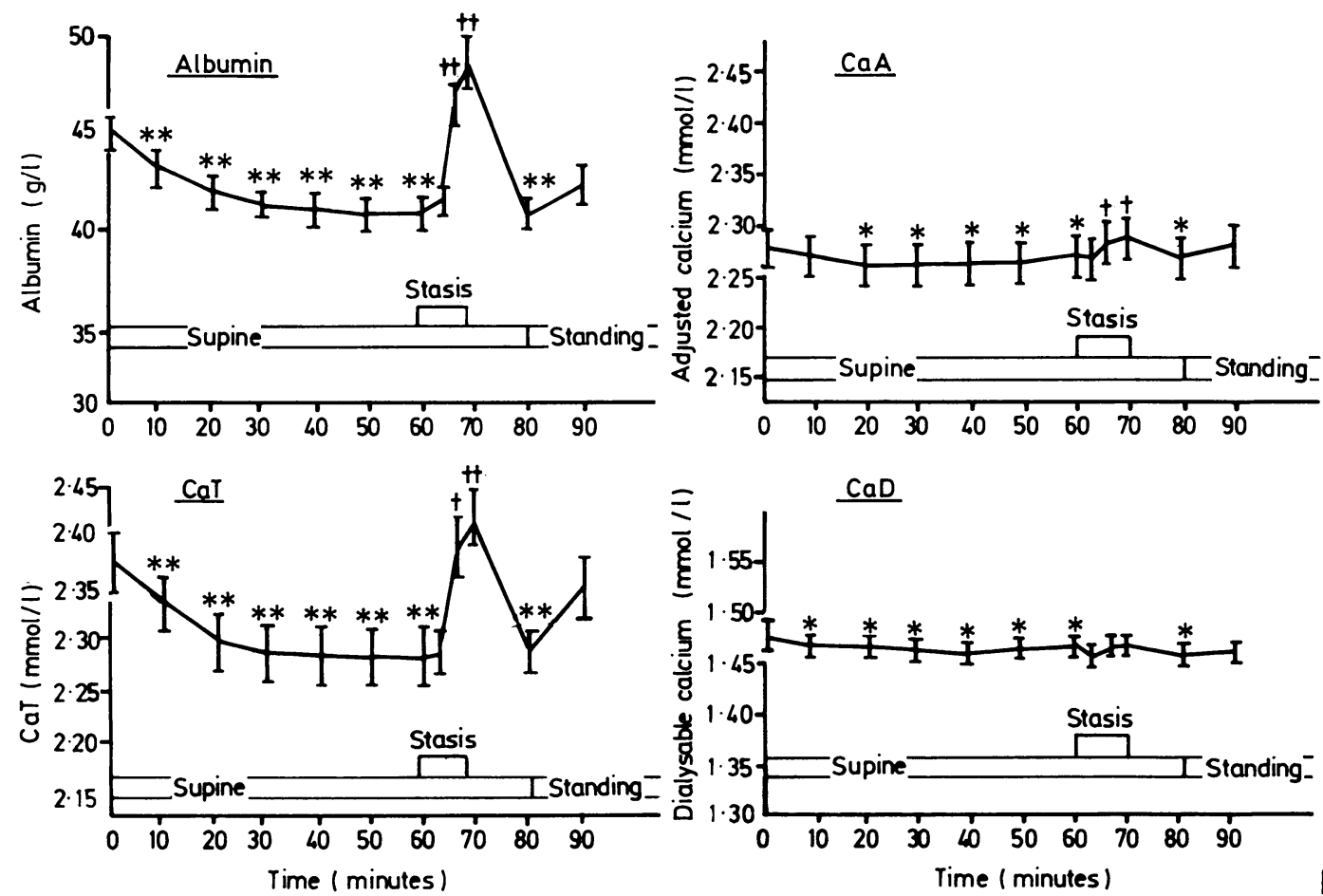

FIG 4-Effects of lying down and of venous stasis on serum albumin, total calcium (CaT), adjusted calcium (CaA), and dialysable calcium $(\mathrm{CaD})$ values in five healthy women and five healthy men volunteers. Results are means and SEM. ${ }^{*} \mathrm{p}<0.005,{ }^{* *} \mathrm{p}<0.01$ compared with value at zero time.

$\dagger \mathrm{p}<0.05, \ddagger \mathrm{p}<0.01$ compared with value at 60 minutes.

Conversion: SI to traditional units-Calcium: $1 \mathrm{mmol} / 1 \approx 4 \mathrm{mg} / 100 \mathrm{ml}$.

further three patients were hyperglobulinaemic (two with myeloma, one with inflammatory arthropathy), and the remaining two were cases of Paget's disease and apnoea in a neonate.

Area 2-Of seven patients with high $\mathrm{CaD}$ and normal $\mathrm{CaT}$ values, two had multiple renal calculi and renal calcification, and a further patient subsequently underwent parathyroidectomy for hyperparathyroidism. Although mild primary hyperparathyroidism was not proved in all of these cases, clinically it was considered possible.

Area 3-All 11 patients with normal $\mathrm{CaD}$ and low $\mathrm{CaT}$ concentrations were hypoalbuminaemic and corrected into the normal range for CaA.

Area 4-Of six patients with low $\mathrm{CaD}$ and normal $\mathrm{CaT}$ values, four had a clinical cause for the hypocalcaemia (one case each of pancreatitis, chronic renal failure, post-thyroidectomy state, recovery phase after cardiac arrest).

In $29\left(9^{.9} 9^{\prime \prime}\right)$ of the 293 cases, therefore, the CaT value was high or low when the $\mathrm{CaD}$ concentration was normal. Probably all these patients were normocalcaemic clinically. In 13 cases $\left(\mathbf{4}^{\prime \prime \prime}\right) \mathrm{CaD}$ was high or low when CaT was normal. In seven of these (54") there were clinical grounds for suspecting a disorder of calcium metabolism.

The correlation coefficient between $\mathrm{CaD}$ and $\mathrm{CaA}$ values was 0.83 (see fig 6). The normal range for CaA used was actually the normal range for $\mathrm{CaT}$ as derived from the blood donor population. This was used because it reduced from 43 cases to 38 the discrepancy between $\mathrm{CaD}$ and $\mathrm{CaA}$ in this patient population when compared with the normal range actually derived from the blood donor population. This was largely because the mean serum albumin concentration was thyroidism. One patient subsequently underwent parathyroidectomy for hyperparathyroidism, and a further patient had calcium gluconate gel applied to the skin for hydrogen fluoride burns. In seven cases there was no obvious cause for hypercalcaemia.

Area 3-Three patients had normal $\mathrm{CaD}$ and low $\mathrm{CaA}$ values. In all three the CaT concentration was normal and there was no reason to suspect an abnormality of calcium metabolism.

Area 4-Fifteen patients had low $\mathrm{CaD}$ and normal $\mathrm{CaA}$ concentrations. Of these, four had chronic renal failure, and two subsequently died; three had pancreatitis; and five were severely ill with various conditions. These 12 patients therefore had clinical conditions previously associated with a low $\mathrm{CaI}$ value. ${ }^{7}$ Acidosis, however, could not be excluded in all patients. In three cases there was no obvious cause for hypocalcaemia.

In 11 cases, therefore, $\mathrm{CaA}$ concentration was high or low when the $\mathrm{CaD}$ value was normal. Probably on clinical grounds all the patients were normocalcaemic. Of the 12 patients in whom the $\mathrm{CaA}$ value was normal when the $\mathrm{CaD}$ concentration was high, probably five $(42 \%)$ were indeed hypercalcaemic. Of the 15 patients in whom the $\mathrm{CaA}$ value was normal when the $\mathrm{CaD}$ value was low, probably $12(80 \%)$ were hypocalcaemic.

\section{Discussion}

The best technique for measuring the physiologically active calcium concentration has been a subject of controversy for 
several years. Although the ionised fraction of calcium has been considered to be the physiologically active moiety,' most laboratories report $\mathrm{CaT}$ concentrations because the techniques of measurement are straightforward and reliable. In recent years a technique for measuring $\mathrm{CaD}$ has been developed, ${ }^{2}+5$ which in our hands is highly correlated with the measurement of $\mathrm{CaI}$ but overcomes many of the problems inherent in that technique. In validation of $\mathrm{CaD}$ as a measure of physiologically active calcium in normal subjects the correlation coefficient between $\mathrm{CaD}$ and $\mathrm{CaI}$ was appreciably higher than the
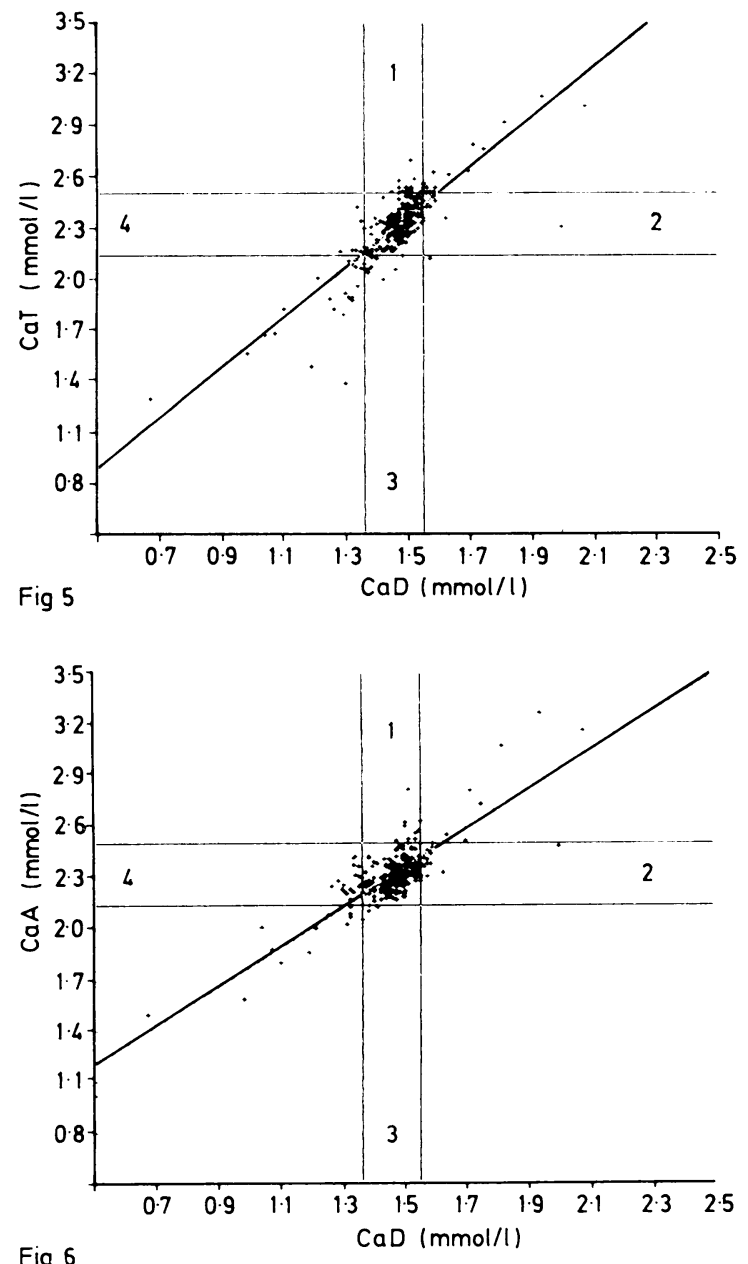

Fig 6

FIG 5-Correlation of dialysable calcium $(\mathrm{CaD})$ with total calcium (CaT) values in 293 consecutive patients. Normal ranges indicated. Area 1: Normal $\mathrm{CaD}$, high CaT. Area 2: High CaD, normal CaT. Area 3: Normal CaD, low CaT. Area 4: Low CaD, normal CaT.

Conversion: SI to traditional units-Calcium: $1 \mathrm{mmol} / 1 \approx 4 \mathrm{mg}$ / $100 \mathrm{ml}$.

FIG 6-Correlation of dialysable calcium (CaD) with adjusted calcium (CaA) values in 293 consecutive hospital patients. Normal ranges indicated. Area 1: Normal CaD, high CaA. Area 2: High $\mathrm{CaD}$, normal CaA. Area 3: Normal CaD, low CaA. Area 4: Low $\mathrm{CaD}$, normal $\mathrm{CaA}$.

Convirsion: SI to traditional units-Calcium: $1 \mathrm{mmol} / 1 \approx 4 \mathrm{mg}$ $100 \mathrm{ml}$.

correlation coefficient between both $\mathrm{CaT}$ and $\mathrm{CaI}$ and $\mathrm{CaA}$ and CaI. Indeed, the calculation of $\mathrm{CaA}$ in these normal subjects resulted in a worse correlation of $\mathrm{CaA}$ with $\mathrm{CaI}$ than the correlation of $\mathrm{CaT}$ with $\mathrm{CaI}$. If it is accepted that the $\mathrm{CaI}$ value is currently the best measure of physiologically active calcium, although influenced by the protein concentration to a small extent, ${ }^{*}$ then $\mathrm{CaD}$ provides a better measure than $\mathrm{CaT}$ or $\mathrm{CaA}$. Measurement of $\mathrm{CaD}$ abolished the difference in the normal range between men and women, as did $\mathrm{CaI}$ but not $\mathrm{CaT}$ or $\mathrm{CaA}$. In patients with chronic renal failure, in whom the $\mathrm{CaI}$ value calculated from $\mathrm{CaT}$ and albumin has a poor correlation with the directly measured $\mathrm{CaI},{ }^{9} \mathrm{CaD}$ was highly correlated with $\mathrm{CaI}$. In our hands, however, so were $\mathrm{CaT}$ and $\mathrm{CaD}$

Technical problems in measuring the $\mathrm{CaI}$ concentration were that the blood had to be collected anaerobically, had to be analysed shortly after collection, and each sample had to be analysed individually, which was time consuming. By contrast, $\mathrm{CaD}$ required no particular precautions for collection or storage, the samples were occasionally analysed weeks after collection, and samples could be batch analysed in a continuous flow fashion.

$\mathrm{CaD}$ was also compared with $\mathrm{CaT}$. In normal subjects $\mathrm{CaT}$ was noticeably affected by posture, the rnain effect occurring within 30 minutes; it was also greatly affected by venous stasis after three minutes, both effects probably being the result of changes in albumin concentration. By contrast, the changes in $\mathrm{CaD}$ with posture and stasis were minimal. Correlation with clinical categorisation is conceptually the most important validation of a biochemical test. In the study of hospital patients, although $\mathrm{CaT}$ and $\mathrm{CaD}$ were highly correlated, there was disagreement whether patients should be categorised as normocalcaemic, hypocalcaemic, or hypercalcaemic in $14.3 \%$ of cases. There were clinical grounds for accepting $\mathrm{CaD}$ as probably correct in $86 \%$ of the cases in which there was discordance. Toffaletti has performed a similar clinical categorisation analysis. ${ }^{10}$ Thus $\mathrm{CaD}$ probably represented the clinical state more accurately than CaT. Nevertheless, it must be accepted that this retrospective clinical categorisation analysis would have been strengthened by other, more definitive diagnostic techniques-for example, parathyroid hormone estimation or parathyroid exploration in the patients with renal stones and marginal increases of calcium concentration.

$\mathrm{CaD}$ was compared to $\mathrm{CaA}$ values in several settings. Numerous formulas for adjusting for variation in the concentration of albumin have been devised, and we selected the simplest and therefore the most widely used. ${ }^{6} \mathrm{CaA}$ largely but not completely overcame the effects of posture and venous stasis on CaT. It was not as well correlated with $\mathrm{CaI}$ as was $\mathrm{CaD}$ in normal subjects. In the study of hospital patients there was a high degree of correlation between $\mathrm{CaD}$ and $\mathrm{CaA}$. Nevertheless, in $13 \%$ of cases there was disagreement over classification of patients into normocalcaemic, hypocalcaemic, and hypercalcaemic groups. There were clinical reasons for accepting the $\mathrm{CaD}$ value as correct in $74^{\circ}$, of these discordant cases. Ladenson et al used 14 algorithms for calculating the corrected calcium concentration from a knowledge of total calcium, protein albumin, and $\mathrm{pH}$ and compared these with the free calcium concentration measured by an ion specific electrode." They concluded that none of the algorithms predicted adequately the free calcium concentration. The calculation of $\mathrm{CaA}$ required measurement of both $\mathrm{CaT}$ and albumin with the inevitable accumulation of precision errors, whereas $\mathrm{CaD}$ required only one measurement. Thus the resources required to measure $\mathrm{CaD}$ are less than those required for $\mathrm{CaA}$.

There are several potential problems with $\mathrm{CaD}$. The first is that $\mathrm{CaD}$ is measured at a fixed $\mathrm{pH}$ no matter what the subject's actual serum $\mathrm{pH}$ is. Clearly the vast majority of patients will have an in vivo serum pH very close to $7 \cdot 4$, so that in most cases this correction will have little or no effect. In some patients with extremely low or high $\mathrm{pH}$, however, $\mathrm{CaD}$ will be 1 elatively inaccurate. This effect was investigated by Toffaletti and Bowers, who showed that the measured concentration of dialysable calcium decreased by approximately $0.05 \mathrm{mmol} / \mathrm{l}$ $(0.2 \mathrm{mg} / 100 \mathrm{ml})$ for each 0.1 unit increase in $\mathrm{pH}$ between $7 \cdot 2$ and $7 \cdot 6 .^{4}$ The major advantage of correcting to a fixed $\mathrm{pH}$ is that it allows the serum sample to be collected without any special precautions, and in our opinion this outweighs the potential inaccuracy in a small number of patients.

Interestingly, the $\mathrm{pH}$ effect might account for the difference in our reference range for $\mathrm{CaD}(1.37-1.56 \mathrm{mmol} / \mathrm{l} ; 5.48-6.24$ $\mathrm{mg} / 100 \mathrm{ml}$ ) compared with that of Toffaletti and Kirvan 
$(1 \cdot 26-1 \cdot 42 \mathrm{mmol} / 1 ; 5 \cdot 04-5 \cdot 68 \mathrm{mg} / 100 \mathrm{ml}) .{ }^{5}$ Those workers used a trometamol (TRIS) buffer which is highly temperature dependent, whereas this is not the case for the imidazole buffer that we employed. Their buffer was made up to $\mathrm{pH} 7.4$ at $37^{\circ} \mathrm{C}$ but used at room temperature. This would produce a rise in $\mathrm{pH}$ to roughly 7.7 at $25^{\circ} \mathrm{C}$, which would be associated with a fall of approximately $0.15 \mathrm{mmol} / 1(0.6 \mathrm{mg} / 100 \mathrm{ml})$ in the measurement of $\mathrm{CaD}$. As the mean of their reference range was $0.125 \mathrm{mmol} / 1(0.5 \mathrm{mg} / 100 \mathrm{ml})$ less than ours this technical difference may account for the differences in the normal ranges. This underlines the critical importance of the $\mathrm{pH}$ of the sample at which $\mathrm{CaD}$ is measured.

Another problem is that currently there is no internationally recognised reference standard for $\mathrm{CaD}$. Our approach has been to calibrate the assay system against a solution of calcium carbonate, but this is open to criticism as it does not allow for the Donnan effect of protein. Nevertheless, in view of the fact that large changes in serum albumin concentration induced by venous stasis had no effect on $\mathrm{CaD}$, the Donnan effect would appear to have no practical relevance. Although the problem of standardisation may be relevant to interpretation of results among different laboratories, once a standard has been developed within a particular laboratory the results will be internally consistent. Furthermore, if this method is widely accepted it should be possible to develop an acceptable international standard.

In favour of the use of $\mathrm{CaD}$ rather than other methods of calcium estimation is that the method is a simple modification of a continuous flow total calcium technique using equipment that has been tried and tested over many years and is readily available. It correlates well with $\mathrm{CaI}$ but has none of the practical problems associated with this technique. Although under many circumstances $\mathrm{CaA}$ gives a clinically equivalent result, calcula- tion requires the measurement of both $\mathrm{CaT}$ and albumin. Now that it is 50 years since the physiological irrelevance of protein associated calcium was first commented on it is time to move away from measuring $\mathrm{CaT}$. In busy biochemical laboratories $\mathrm{CaD}$ estimation is an efficient and cost effective answer.

We thank Mrs Margaret Miller, of the NH and MRC unit in clinical epidemiology, University of Western Australia, who provided some of the blood samples for analysis, and Miss Rowena Devlin, of the department of endocrinology and diabetes, Sir Charles Gairdner Hospital, who performed the CaI measurements.

\section{References}

McLean FC, Hastings AB. A biological method for the estimation of calcium ion concentration. $\mathcal{F}$ Biol Chem 1934;107:337-50.

Toffaletti J, Savory J, Gitelman HJ Continuous-flow determination of dialysable calcium in serum. Clin Chem 1977;23:1258-63.

Moore EW. Ionized calcium in normal serum, ultrafiltrates and whole blood determined by ion exchange electrodes. $\mathcal{F}$ Clin Invest 1970;49:318-34.

4 Toffaletti J, Bowers GN. Improvement in and clinical utility of a continuous-flow method for routine measurement of dialysable (ultrafiltrable) calcium. Clin Chem 1979;25:1939-43

5 Toffaletti J, Kirvan K. Spectrophotometric micromethod for measurement of dialysable calcium by use of cresolphthalein complexone and continuous-flow analysis. Clin Chem 1980;26:1562-5.

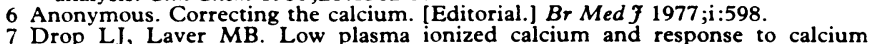
Drop LJ, Laver MB. Low plasma ionized calcium and response to calcium
therapy in critically ill man. Anesthesiology $1975 ; 43: 300-6$. therapy in critically ill man. Anesthesiology $1975 ; 43: 300-6$.
ayne RB. Clinically significant effect of protein concentration on ion-selective electrode measurements of ionized calcium. Ann Clin Biochem 1982;19:233-7.
conceicao SC, Weightman D, Smith PA, Luno J, Ward MK, Kerr DNS. Serum ionised calcium concentration: measurement versus calculation. Serum ionised calcium

10 Toffaletti J. Total, ultrafiltrable, dialysable and ionised calcium measurements in randomly selected samples compared with clinical diagnoses. Ann Clin Biochem $1983 ; 20: 349-52$.

11 Ladenson JH, Lewis JW, Boyd JC. Failure of total calcium corrected for protein, albumin and $\mathrm{pH}$ to correctly assess free calcium status. $\mathcal{F}$ Clin Endocrinol Metab $1978 ; 46: 986-93$.

(Accepted 30 October 1984)

\begin{abstract}
Naloxone abolished the rise in body temperature seen after bicycle ergometer tests performed by 10 healthy men. This suggests that endogenous opiates play a part in thermal regulation during muscular exercise.

\section{Introduction}

The effect of opiates on core temperature has been the subject of many studies. Evidence shows that endogenous opiates, in

Academisch Ziekenhuis, Vrije Universiteit Brussel, Belgium

$\mathrm{K}$ DE MEIRLEIR, MD, internist

L VANHAELST, MD, PHD, professor of endocrinology

Institut für Kreislaufforschung und Sportmedizin, Deutsche Sporthochschule, Cologne, Federal Republic of Germany T ARENTZ, medical student

W HOLLMANN, MD, PHD, professor of cardiology and sports medicine

Correspondence to: $\mathrm{Dr} \mathrm{K}$ De Meirleir, Internal Medicine, AZ-VUB, Laarbeeklaan 101, B-1090 Brussels, Belgium.
\end{abstract}

particular endorphins, have a role in the central control of body temperature. ${ }^{1-4}$ Because body temperature rises during dynamic muscular exercise we were intrigued to know whether endogenous opiates play a part in this phenomenon. We therefore studied the effect of naloxone (an opiate antagonist) on the changes in body temperature induced by exercise.

\section{Subjects, methods, and results}

Ten healthy men aged 22-28 years, who regularly participated in various sporting activities, underwent a graded ergometer test on three occasions. They exercised on a bicycle ergometer with electric brakes (Ergometric systems 380B, Siemens Elema, Sweden), and on each occasion an identical protocol was used. The tests were performed in the same laboratory at constant room temperature and humidity, at the same time of day, and with an interval of at least four days between each test for each subject.

The first test served as a control. In the second and third tests either placebo ( $5 \mathrm{ml}$ saline) or $2 \mathrm{mg}$ naloxone (naloxone hydrochloride $0.4 \mathrm{~g} / \mathrm{l}$, Dupont de Nemours, Belgium) was administered intravenously five minutes before exercising. The order of the placebo and naloxone tests was randomised and double blind; five subjects received placebo first and five received naloxone first to minimise carryover effects. The temperature in the laboratory was kept constant at $20^{\circ} \mathrm{C}$ and the humidity at $60 \%$. Sublingual temperature was 